\title{
Pediatrik Kafa Travması Hastalarında Diffüz Aksonal Hasar Sonrası Kalıcı Nörokognitif Sekele Etki Eden Faktörler
}

\author{
Factors Affecting Permanent Neurological Defects in Pediatric \\ Patients with Diffuse Axonal Injury after Trauma
}

\author{
Ayşe Filiz YETIMAKMAN', Rahsan GÖÇMEN²
}

${ }^{1}$ Kocaeli Üniversitesi, Tıp Fakültesi, Çocuk Sağlı̆̆ı ve Hastalıkları Anabilim Dalı, Çocuk Yoğun Bakım Bilim Dalı, Kocaeli, Türkiye
${ }^{2}$ Hacettepe Üniversitesi, Tıp Fakültesi, Radyoloji Anabilim Dalı, Ankara, Türkiye

\section{ÖZ}

Amaç: Bir parankimal travmatik hasarlanma tipi olan diffüz aksonal hasar (DAH), kafa travması geçiren çocuk hastalarda akut ve kronik dönemde ciddi nörokognitif bozukluklara sebep olabilmektedir. Bu çalşmada klinik ve radyolojik bulgulardan hangilerinin ağır hasar ile ilişkili olduğunu saptanması amaçlanmıştır.

Gereç ve Yöntemler: Çalışmamızda 2012-2017 yılları arasında ağır kafa travması sonrası çocuk yoğun bakım ünitesinde izlenen otuz dokuz hastanın verileri incelenmiştir. DAH ön tanısı ile manyetik rezonans görüntüleme (MRG) yapılmış hastaların başvurudaki yaş, Glasgow Koma Skalası (GKS), Pediatric Risk of Mortality (PRISM) skoru, taburculukta Glasgow Outcome Skalası (GOS), vital bulgular, laboratuvar bulguları, hastanede kalma sürelerine ulașımıştır. DAH ile uyumlu lezyon yükü, ayrıca bu lezyonların beyindeki anatomik yerleșimleri not edilmiştir. DAH (+) saptanan grup ile saptanmayan grup karşılaştııımış, ayrıca hangi parametrelerin GOS üzerinde anlamlı etkisi olduğu incelenmiştir.

Bulgular ve Sonuçlar: Hastaların 29'unda DAH ile uyumlu MRG bulgusu saptanırken, kalan 10 hastada ise beyin MRG'de DAH saptanmadı. Bu iki grubun karşılaștııımasında PRISM, GOS ve GKS skorları ve hastanede yatış süreleri farkı bulunmuştur. DAH (+) hasta grubunda GKS ve PRISM skorlarının, ayrıca hastane yatış süresinin GOS ile anlamlı korelasyonu saptanmıştır. Hastalarda toplam lezyon yükü ile GKS ya da GOS arasında anlamlı bir ilişki bulunamamıştır. Talamus ve beyin sapında lezyon bulunan hastalarda GKS diğer hastalara göre anlamlı düşüklük bulunurken GOS ile ilgili böyle bir ilișki gösterilememiștir. Çalıșmamızın sonuçları diffüz aksonal hasarın hafif kafa travmalarına göre daha ciddi nörokognitif bozukluğa sebep olduğunu, uzun hastane yatışı ve rehabilitasyon gerektirdiğini göstermektedir. Ancak prognoz ve kalıı hasar için belirleyici faktörler konusunda hem klinik hem de radyolojik bulguları içeren geniş kohort çalışmalara intiyaç vardır.

Anahtar Sözcükler: Beyin hasarı, Diffüz aksonal hasar, Kritik hastalık

\section{ABSTRACT}

Objective: Diffuse axonal injury (DAl), which is a type of traumatic parenchymal injury, can result in acute or chronic severe neurocognitive defects in children who have had traumatic brain injury. In this study we aimed to define which clinical and radiological parameters are related to severity of morbidity.

Material and Methods: Data was gathered about 39 children who were admitted to pediatric intensive care unit after severe trauma. Data was recorded on age, Glasgow Coma Scale (GKS), Pediatric Risk of Mortality (PRISM)

(1) YETIMAKMAN AF GÖÇMEN G
Çıkar Çatışması / Conflict of Interest: Tüm yazarlar adına, sorumlu yazar çıkar çaıışması olmadığııı belirtir.

0000-0002-9334-4464 Etik Kurul Onayı / Ethics Committee Approval: Bu callsmada ulusal ve uluslararası etik kurallara uyulmuștur. Calıșma için, Hacettepe Üniversites 0000-0002-0223-9336 Girișimsel Olmayan Klinik Araștırmalar Etik Kurulu'ndan GO 16/696-09 karar no ve 06.12.2016 tarih ile onay alinmıștır. Kaytt sirasinda veliler tarafindan araştırmaya katılım için bilgilendirilmiş bir onay imzalanmış̧ır.

Yazarların katkısı / Contribution of the Authors: YETiMAKMAN AF: Araștırma ve/veya makalenin hipotezini veya fikrini olușturan, Sonuçlara ulașmak için planlama/metodoloji belirleme, Araștırma/çalıșmanın sorumluluğunu üstlenmek, ilerlemenin seyrini denetlemek, Hasta takibinde sorumluluk almak, ilgill biyolojik malzemelerin toplanması, veri yönetimi ve raporlama, deneylerin yürütülmesi, Sonuçlarn mantiksal olarak Yorumlanması ve sonuçlandirlıması, Çalıșma için gerekli literatür taramasinda sorumluluk almak, Çalişmanin bütününün veya önemli bölümlerinin yazımında sorumluluk almak, Yazım ve

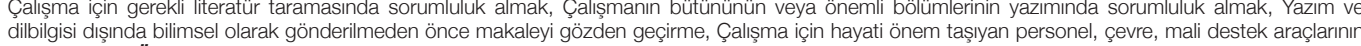
sağlanması. GÖÇMEN R: Araștırma ve/veya makalenin hipotezini veya fikrini olușturan, Sonuçlara ulașmak için planlama/metodoloji belirleme, Araștırma/ çalıșmanın sorumluluğunu üstlenmek, ilerlemenin seyrini denetlemek, Çalıșmanın bütününün veya önemli bölümlerinin yazımında sorumluluk almak, Yazım ve dilbilgisi dıșinda bilimsel olarak gönderilmeden önce makaleyi gözden geçirme.

Atıf yazım șekli / How to cite : Yetimakman AF, Göçmen R. Pediatrik Kafa Travması Hastalarnda Diffüz Aksonal Hasar Sonrası Kalııı Nörokognitif Sekele Etki Eden Faktörler. Türkiye Çocuk Hast Derg 2020;14:5;379-384.
Yazıșma Adresi / Correspondence Address:

\section{A. Filiz YETiMAKMAN}

Kocaeli Üniversitesi, Tıp Fakültesi, Çocuk Sağı̆ğı ve Hastalıkları Anabilim Dalı,

Çocuk Yoğun Bakım Bilim Dalı, Kocaeli, Türkiye

E-posta: filizyetimakman@hotmail.com
Geliş tarihi / Received : 14.07.2020 Kabul tarihi / Accepted : 24.08.2020 Elektronik yayın tarihi : :17.09.2020 Online published

DOI: 10.12956/tchd.768523 
score, Glasgow Outcome Scale (GOS), vital signs, laboratory findings and duration of hospital stays of children who have had magnetic resonance imaging (MRI) to diagnose DAI. Number of DAl lesions and their anatomical distribution within the brain were recorded. Parameters were compared between the groups with and without DAl. We also aimed to define clinical and radiological parameters which were related to GOS.

Results and Conclusion: Twenty nine patients had DAl lesions on MRI. In comparison of the patients with and without DAl; PRISM, GOS and GCS and also durations of hospital stay were significantly different. In the group with DAl lesions, GOS was correlated with GCS and PRISM scores as well as durations of hospital stay. Neither GOS nor GCS were found to have a relationship with total number of lesions. GCS were significantly lower in patients who had lesions in thalamus and brain stem, but no relationship could be defined between GOS and position of lesions. Results of our study demonstrate that DAl causes more severe neurocognitive defects than mild brain injuries and patients need longer durations of hospital stay and rehabilitation. Larger cohort studies including clinical and radiological data are needed in order to define factors affecting prognosis and permanent damage.

Key Words: Brain injuries, Diffuse axonal injury, Critical care

\section{GiRiş}

Ülkemizde ve dünyada çocuk yoğun bakım ünitelerinde ağır kafa travmasına maruz kalmış hastalar sıklıkla izlenmektedir. Bu hastalarda beyin kanaması, beyin ödemi ve kafa içi basıncın artması ani gelişen hayatı tehdit eden durumlar oluşturmakta; kontüzyon, diffüz aksonal hasar gibi durumlar ise kognitif fonksiyonlarda geçici veya kalıcı bozukluklara sebep olmaktadır. Bu hasarların beyindeki etkilerinin patofizyolojisinin tanımlanması ve hasarı sınırlayıcı tedavi ve önlemlerin belirlenmesi önemli bir araştırma sahasını oluşturmaktadır (1). Pediyatrik kafa travması geçiren hastalarda kaza ile ilişkili, kaza öncesi ve özellikle akut dönemdeki faktörlerin sağ kalım ve beyin hasarı üzerine etkilerini inceleyen klinik çalışmalar mevcuttur (2-4). Çeşitli çalışma grupları tarafından multidisipliner yaklaşımla hastaların sağkalım ve iyileşme durumlarının nasıl etkilenebileceğine dair çalışmalar yapılmıştır $(5,6)$. Ancak bu çalışmalar çoğunlukla çeşitli beyin hasarı tiplerinin karmasından oluşmaktadır, özel hasar tiplerinde, sadece bu hasara sahip hastalarda yapılacak çalışmalara intiyaç vardır.

Diffüz aksonal hasar (DAH) terimi kafa travmalarında görülebilen parankimal travmatik hasarlanmayı adlandırmak için kullanımaktadır. Yüksek enerjili travma vakalarında ve akselerasyon - deselerasyon içeren travmalarda görülme sıklığının arttığı bilinmektedir (7). Yüksek enerjili travmaya maruz kalan ve bilgisayarlı tomografi görüntülemesi normal veya kliniği açıklamayacak kadar hafif travma bulguları barındırmasına rağmen, hastanın bilinç durumunun uzun süre normale dönmemesi durumunda DAH'dan şüphelenilmelidir. Bu durumda tercih edilecek görüntüleme yöntemi ise manyetik rezonans görüntüleme (MRG) olmalıdır. Özellikle difüzyonağırlıklı görüntüleme (DAG) ve duyarlıı̆a-dayalı görüntüleme veya daha yaygın ve Türkçe'de de yerleşmiş söylenişi ile SWI (susceptibility-weighted imaging) gibi spesifik MRG sekansları ile DAH yüksek duyarıııkla gösterilebilir $(8,9)$. DAH, ciddi ve kalıcı nörolojik bozukluklara sebep olabildiğinden, travmaya bağlı faktörlerden ve travma sonrasında izlenen klinik değişkenler ve tedavilerden hangilerinin nörolojik hasarın ağırlığı ile ilişkili olduğunu saptamak önemlidir.
Çalıșmamızda kafa travması sonrası DAH tanısı ile izlenmiș olan çocuk hastaların taburculuktaki nörolojik hasarları derecelendirilerek çeşitli klinik verilerle hasarın derecesi karşılaştırılmıştır. Çalışmamızın amacı bu veriler ile nörolojik bozukluk derecesinin korelasyonuna bakarak klinikte takip ve tedavi hedeflerini belirlemektir.

\section{GEREÇ ve YÖNTEMLER}

Çalışmamızda 2012-2017 yılları arasında ağır kafa travması sonrası çocuk yoğun bakım ünitesinde izlenen 18 yaş altında otuz dokuz hastanın verileri incelenmiştir. Ünitemizde ağır kafa travması olan hastalarda yüksek enerjili travmaya maruz kalan ve 48 saatten uzun süre bilinç durumu normale dönmeyen hastalarda DAH olabileceği düşünülerek hasta stabilize edildikten sonra travmanın kırk sekiz ila yetmiş ikinci saati arasında DAG ve SWI sekanslarını içeren travma protokolü ile MRG rutin olarak yapılmaktadır.

Çocuk yoğun bakım ünitesinde orta veya ağır kafa travması nedeniyle izlenen, DAH ön tanısı ile MRG incelemesi yapılmış otuz dokuz hastanın başvurudaki yaş, klinik bulgular, Glasgow koma skalası (GKS), Pediatric Risk of Mortality (PRISM) skoru, taburculukta Glasgow Outcome Skalası (GOS), vital bulgular (kalp tepe atımı, sistolik, diyastolik ve ortalama tansiyon), laboratuvar bulguları (Ph, glukoz, hemoglobin, hematokrit), komada kalma süreleri, ventilatörde kalma süreleri, hastanede kalma sürelerine ulaşılmıştır.

Beyin MRG'de DAH ile uyumlu difüzyon kısıtlılığı gösteren lezyonlar ve/veya SWI sekansında hemorajik lezyonlar tek tek sayılarak toplam difüzyon lezyonu ve toplam mikrohemoraji lezyonu yükü ayrı ayrı hesaplanmıştır. Ayrıca bu lezyonların beyindeki anatomik yerleşimleri not edilmiştir.

PRISM skoru hastaların genel ağırık durumunu değerlendirmek için kullanılan bir skor olup yoğun bakıma yatışın ilk 24 saatindeki en kötü klinik ve laboratuvar bulguları temel alınmıştır. Hastalardaki kognitif hasarın derecesi Glasgow Outcome Skalası (GOS) ile değerlendirilmiş olup, hasta dosyasındaki 
taburculuk gününde kaydedilmiş nörolojik ve genel muayene bulguları dikkate alınarak hesaplanmıştır.

MRG bulgularında DAH saptanan grup hasta grubu olarak belirlenmiştir. Buna göre hasta grubunda hangi parametrelerin GOS üzerinde anlamlı etkisi olduğu incelenmiştir.

Çalışma için, Hacettepe Üniversitesi Girişimsel Olmayan Klinik Araștırmalar Etik Kurulu'ndan GO 16/696-09 karar no ve 06.12.2016 tarih ile onay alınmıştır.

Çalışmanın verileri Statistical Package for Social Sciences (SPSS) 22.0 (SPSS Inc., Chicago, IL) programı kullanılarak değerlendirilmiștir. Tanımlayıcı istatistikler ortalama \pm standart sapma ve sıklıklar yüzde (\%) olarak belirtilmiştir. Klinik bulgulara göre gruplar arasında verilerin değerlendirilmesinde independent t testi, nonparametric Mann-Whitney $U$ testi, varyans analizi, Spearman korelasyon analizi ve ki-kare testi kullanılmıştır. $\mathrm{p}<0.05$ için sonuçlar istatistiksel olarak anlamlı kabul edilmiştir.

\section{SONUÇLAR}

Araştırma kapsamında toplam 39 hasta incelendi. İncelenen hastaların yaş ortancası 55 (min:2-maks:211) ay olup \%69.2'si erkek, \%30.8'i kız hastaydı. Tüm hasta grubunda demografik veriler ve klinik bulgular Tablo I'de özetlenmiştir. İncelenen 39 hastanın 29'unda (\%74.4) DAH ile uyumlu MRG bulgusu saptanırken, kalan 10 hastada (\%25.6) ise beyin MRG'de DAH saptanmadı. MRG ile DAH saptanmış olan hastalarla diğer hastaların karşılaştırmasında PRISM, GOS ve GKS skorları ve hastanede yatış süreleri farklı bulunmuştur $(p=0.003, p=0.005$, $p=0.006, p=0.001$ ). Iki grubun karşlaş̧ırması Tablo I'de özetlenmişsir. DAH (+) hasta grubunda klinik ve laboratuvar bulgulardan yalnızca GKS ve PRISM skorlarının, ayrıca hastane yatış süresinin GOS ile anlamlı korelasyonu saptanmış olup, bu durum GOS düşük olan hastaların daha ağır hastalık ciddiyetine sahip olduğunu göstermektedir. ( $p<0.001, p=0.011, p=0.017)$ Diğer klinik, laboratuvar ve görüntüleme bulguları ile GOS arasında anlamlı ilişki saptanmamıştır (Tablo III).

Diffüz aksonal hasar saptanan hastalarda en sık tutulan anatomik bölge korpus kallozumdu. Hastalarda, en az 1 en fazla 11 anatomik bölgede tutulum izlendi. Hastalardan 11 'inde bazal ganglionlarda, 13'ünde talamusta, 3'ünde internal kapsülde, 13'ünde beyin sapında, 13'ünde serebellumda, 25'inde korpus kallozumda lezyonlar mevcuttu. Difüzyon-ağırlıklı görüntülemede lezyon sayısı medyan 8 (1-30)'dı. SWI görüntülemede mikrohemoraji lezyon yükü medyan 16 (1-42)'dı. Hastalarda toplam lezyon yükü ile GKS ya da GOS arasında anlamlı bir ilișki bulunmadı. Hastalar her bir anatomik bölgede lezyon bulunup bulunmamasına göre gruplanarak lezyon varlığının skorlar ile korelasyon gösterip göstermediği de incelendi. Internal kapsülde lezyon olan hasta $(n=3)$ ve korpus kallosumda lezyon olmayan hasta $(n=4)$ sayısı çok az olduğundan karşısş̦tırmalar değerlendirme dışı bırakıldı. Talamus ve beyin sapında lezyon bulunan hastalarda GKS skorunda diğer hastalara göre anlamlı düşüklük bulunurken ( $p=0.019, p=0.036$ ), GOS ile ilgili böyle bir ilişki gösterilemedi. Hastalarda tutulum görülen anatomik bölgelerin dağlımı ve GOS GKS ilişkisi Tablo IV'te gösterilmiștir.

Tablo I: Tüm hasta grubunda demografik veriler ve klinik bulgular.

\begin{tabular}{l|c}
\hline \multicolumn{1}{c}{$(\mathbf{n = 3 9 )}$} & Ortanca (en küçük - en büyük) \\
\hline Yaş (ay) & $55(2-211)$ \\
\hline PRISM $^{*}$ & $7(0-23)$ \\
\hline Vücut Ağırlığı (kg) & $18(5-70)$ \\
\hline Kalp tepe atımı/dk & $125(65-165)$ \\
\hline Tansiyon (sistolik) & $100(75-120)$ \\
\hline Tansiyon (diyastolik) & $60(40-80)$ \\
\hline Tansiyon (ortalama) & $70(51-100)$ \\
\hline GKS $^{\dagger}$ & $8(3-15)$ \\
\hline GOS $^{\ddagger}$ & $3(2-5)$ \\
\hline pH & $7.35(6.5-7.5)$ \\
\hline Glukoz (mg/dL) & $162(50-359)$ \\
\hline Hemoglobin (g/dL) & $10.6(4.7-16.4)$ \\
\hline Hematokrit & $32.8(16.7-47.7)$ \\
\hline Koma Süresi - gün (n=22) & $3(1-31)$ \\
Ventilasyon Süresi- gün (n=25) & $5(1-28)$ \\
Hastane Süresi - gün & $23(2-137)$ \\
\hline
\end{tabular}

*Pediatric Risk of Mortality, ${ }^{+}$Glasgow koma skalasl, ${ }^{*}$ Glasgow outcome skalası 
Tablo II: Diffüz Aksonal Hasar (DAH) olan ve olmayan grupların klinik özellikleri karşılaştırması.

\begin{tabular}{|c|c|c|c|}
\hline & $\begin{array}{c}\text { DAH (-) } \\
(n=10)\end{array}$ & $\begin{array}{c}\text { DAH (+) } \\
(n=29)\end{array}$ & \multirow{2}{*}{$\mathbf{p}$} \\
\hline & $\begin{array}{c}\text { ortanca } \\
\text { (en küçük - en büyük }\end{array}$ & $\begin{array}{c}\text { ortanca } \\
\text { (en küçük - en büyük }\end{array}$ & \\
\hline Yaş (ay) & $48(5-203)$ & $59(2-211)$ & 0.432 \\
\hline PRISM $^{*}$ & $0(0-10)$ & $11(0-23)$ & 0.003 \\
\hline Vücut Ağırlığı (kg) & $18(10-70)$ & $18(5-70)$ & 0.887 \\
\hline Kalp tepe atımı/dk & $117.5(75-140)$ & $128(65-165)$ & 0.206 \\
\hline Tansiyon (sistolik) & $100(90-120)$ & $95.0(75-120)$ & 0.111 \\
\hline Tansiyon (diastolik) & $60(50-80)$ & $55(40-75)$ & 0.444 \\
\hline Tansiyon (ortalama) & 74 (66-93) & $70(51-100)$ & 0.357 \\
\hline $\mathbf{G K S}^{\dagger}$ & $12(7-13)$ & $7(3-15)$ & 0.005 \\
\hline GOS & $5(2-5)$ & $3(2-5)$ & 0.006 \\
\hline $\mathrm{pH}$ & 7.36 (7.19-7.49) & 7.35 (6.50-7.50) & 0.128 \\
\hline Glukoz (mg/dL) & $159(95-231)$ & $162(50-359)$ & 0.554 \\
\hline Hemoglobin (g/dL) & $12.1(8.9-15.9)$ & $10.6(4.7-16.4)$ & 0.270 \\
\hline Hematoktrit (\%) & $36.8(27.8-47.0)$ & $32.3(16.7-47.7)$ & 0.200 \\
\hline Hastane Süresi-gün & $11.5(2-24)$ & $26(3-137)$ & 0.001 \\
\hline
\end{tabular}

Koma ve mekanik ventilasyon öyküsü olan DAH(-) hasta sayısı düşük olduğundan karşılaştırma yapılmamıştır. *Pediatric Risk of Mortality, ${ }^{\dagger}$ Glasgow koma skalası, ₹Glasgow outcome skalası

Tablo III: Diffüz Aksonal Hasar (DAH) olan hastalarda klinik Özelliklerin GOS ile korelasyon ilișkisi.

\begin{tabular}{l|r|r} 
& \multicolumn{1}{c}{ DAH (+) (n=29) } & GOS \\
\hline Yaş & r & 0.454 \\
\hline PRISM ${ }^{*}$ & 0.145 & 0.011 \\
\hline Vücut Ağırlı̆ı (kg) & -0.466 & 0.392 \\
\hline Kalp tepe atımı/dk & 0.165 & 0.154 \\
\hline Tansiyon (sistolik) & -0.271 & 0.068 \\
\hline Tansiyon (diastolik) & 0.344 & 0.408 \\
\hline Tansiyon (ortalama) & 0.160 & 0.198 \\
\hline GKS & 0.246 & $<0.001$ \\
\hline pH & 0.729 & 0.207 \\
\hline Glukoz (mg/dL) & 0.242 & 0.111 \\
\hline Hemoglobin( g/dL) & -0.302 & 0.419 \\
\hline Hematoktrit (\%) & 0.156 & 0.456 \\
\hline Hastane Süresi-gün & 0.144 & 0.017 \\
\hline
\end{tabular}

r: Spearman korelasyon katsayısı, *Pediatric Risk of Mortality, GKS: Glasgow koma skalası, GoS:Glasgow outcome skalası.

\section{TARTIŞMA}

Çalışmamızda toplam 39 hasta incelenmiş, MRG ile DAH saptanmış olan hastaların PRISM ,GKS, GOS skorları ve hastanede yatış süreleri DAH ile uyumlu bulgu saptanmayan hastalardan anlamlı derecede farklı bulunmuştur. DAH (+) hasta grubunda klinik ve laboratuvar bulgulardan yalnızca GKS ve PRISM skorlarının, ayrıca hastane yatış süresinin GOS ile anlamlı korelasyonu saptanmıştır. Talamus ve beyin sapında lezyon bulunan hastalarda GKS anlamlı düşük bulunurken, GOS ile ilgili böyle bir ilişki gösterilememiştir.

Travmatik beyin hasarının sonuçlarının gelişimsel olarak yaşla değişebildiğine dair veriler mevcuttur (10). Çalışmamızda iki grubun yaşları benzer olup diğer klinik faktörler açısından karşılaştırma yapıımıştır. Hastalarımızda DAH ile uyumlu bulgular saptanan grupta GKS, GOS ve hastane yatış sürelerinin anlamlı olarak farklı bulunması diffüz aksonal hasara bağlı hem başvuruda hem de hastane taburculuğunda nörokognitif 
Tablo IV: DAH (+) hastaların lezyon yerleri arasında GKS ve GOS skorlarının dağııımı.

\begin{tabular}{|c|c|c|c|c|c|c|c|c|}
\hline & & \multirow[b]{2}{*}{$\mathbf{n}$} & \multicolumn{2}{|r|}{ GKS $^{*}$} & \multirow[b]{2}{*}{$p^{\S}$} & \multicolumn{2}{|r|}{ GOS } & \multirow[b]{2}{*}{$\mathbf{p}^{\|}$} \\
\hline & & & ort \pm SD & $\begin{array}{c}\text { ortanca } \\
\text { (en küçük - en büyük) }\end{array}$ & & ort \pm SD & $\begin{array}{c}\text { ortanca } \\
\text { (en küçük - en büyük) }\end{array}$ & \\
\hline $\begin{array}{l}\text { Bazal } \\
\text { Ganglion }\end{array}$ & $\begin{array}{l}\text { Yok } \\
\text { Var }\end{array}$ & $\begin{array}{l}18 \\
11\end{array}$ & $\begin{array}{l}8.33 \pm 3.66 \\
6.82 \pm 2.18\end{array}$ & $\begin{array}{l}7(3-15) \\
7(3-9)\end{array}$ & 0.226 & $\begin{array}{l}3.61 \pm 1.09 \\
3.09 \pm 0.83\end{array}$ & $\begin{array}{l}3(2-5) \\
3(2-5)\end{array}$ & 0.276 \\
\hline Talamus & $\begin{array}{l}\text { Yok } \\
\text { Var }\end{array}$ & $\begin{array}{l}16 \\
13\end{array}$ & $\begin{array}{l}9.00 \pm 3.39 \\
6.23 \pm 2.32\end{array}$ & $\begin{array}{l}9(3-15) \\
6(3-11)\end{array}$ & 0.019 & $\begin{array}{l}3.69 \pm 1.14 \\
3.08 \pm 0.76\end{array}$ & $\begin{array}{l}3(2-5) \\
3(2-5)\end{array}$ & 0.199 \\
\hline İnternal kapsül & $\begin{array}{l}\text { Yok } \\
\text { Var }\end{array}$ & $\begin{array}{c}26 \\
3\end{array}$ & $\begin{array}{l}7.85 \pm 3.37 \\
7.00 \pm 1.73\end{array}$ & $\begin{array}{l}7(3-15) \\
6(6-9)\end{array}$ & 0.675 & $\begin{array}{l}3.46 \pm 0.95 \\
3.00 \pm 1.73\end{array}$ & $\begin{array}{l}3(2-5) \\
2(2-5)\end{array}$ & 0.350 \\
\hline Beyin sapı & $\begin{array}{l}\text { Yok } \\
\text { Var }\end{array}$ & $\begin{array}{l}16 \\
13\end{array}$ & $\begin{array}{l}8.88 \pm 3.16 \\
6.38 \pm 2.84\end{array}$ & $\begin{array}{l}9(3-15) \\
6(3-12)\end{array}$ & 0.036 & $\begin{array}{l}3.75 \pm 1.13 \\
3.00 \pm 0.71\end{array}$ & $\begin{array}{r}3.5(2-5) \\
3(2-5)\end{array}$ & 0.092 \\
\hline Serebellum & $\begin{array}{l}\text { Yok } \\
\text { Var }\end{array}$ & & $\begin{array}{l}7.67 \pm 4.10 \\
7.82 \pm 2.8\end{array}$ & $\begin{array}{l}6(3-15) \\
7(3-13)\end{array}$ & 0.900 & $\begin{array}{l}3.75 \pm 0.96 \\
3.18 \pm 1.02\end{array}$ & $\begin{array}{l}3(3-5) \\
3(2-5)\end{array}$ & 0.152 \\
\hline Frontal lob & $\begin{array}{l}\text { Yok } \\
\text { Var }\end{array}$ & $\begin{array}{c}7 \\
22\end{array}$ & $\begin{array}{l}8.57 \pm 4.20 \\
7.50 \pm 2.92\end{array}$ & $\begin{array}{l}7(3-15) \\
7(3-13\end{array}$ & 0.454 & $\begin{array}{l}3.29 \pm 1.25 \\
3.46 \pm 0.96\end{array}$ & $\begin{array}{l}3(2-5) \\
3(2-5)\end{array}$ & 0.600 \\
\hline Parietal lob & $\begin{array}{l}\text { Yok } \\
\text { Var }\end{array}$ & $\begin{array}{l}17 \\
12\end{array}$ & $\begin{array}{l}7.59 \pm 3.41 \\
8.00 \pm 3.07\end{array}$ & $\begin{array}{l}7(3-13) \\
8(3-15)\end{array}$ & 0.742 & $\begin{array}{l}3.35 \pm 1.06 \\
3.50 \pm 1.00\end{array}$ & $\begin{array}{l}3(2-5) \\
3(2-5)\end{array}$ & 0.679 \\
\hline Temporal lob & $\begin{array}{l}\text { Yok } \\
\text { Var }\end{array}$ & $\begin{array}{c}9 \\
20\end{array}$ & $\begin{array}{l}7.89 \pm 4.14 \\
7.70 \pm 2.85\end{array}$ & $\begin{array}{l}6(3-15) \\
7(3-13)\end{array}$ & 0.887 & $\begin{array}{l}3.56 \pm 1.42 \\
3.35 \pm 0.81\end{array}$ & $\begin{array}{l}3(2-5) \\
3(2-5)\end{array}$ & 0.945 \\
\hline Oksipital lob & $\begin{array}{l}\text { Yok } \\
\text { Var }\end{array}$ & $\begin{array}{c}21 \\
8\end{array}$ & $\begin{array}{l}7.95 \pm 3.50 \\
7.25 \pm 2.49\end{array}$ & $\begin{array}{l}7(3-15) \\
7(3-11)\end{array}$ & 0.609 & $\begin{array}{l}3.43 \pm 1.08 \\
3.38 \pm 0.92\end{array}$ & $\begin{array}{l}3(2-5) \\
3(2-5)\end{array}$ & 0.943 \\
\hline İnsular bölge & $\begin{array}{l}\text { Yok } \\
\text { Var }\end{array}$ & $\begin{array}{l}16 \\
13\end{array}$ & $\begin{array}{l}7.88 \pm 3.76 \\
7.62 \pm 2.57\end{array}$ & $\begin{array}{r}6.5(3-15) \\
7(4-13)\end{array}$ & 0.834 & $\begin{array}{l}3.50 \pm 1.16 \\
3.31 \pm 0.86\end{array}$ & $\begin{array}{l}3(2-5) \\
3(2-5)\end{array}$ & 0.779 \\
\hline Singulat girus & $\begin{array}{l}\text { Yok } \\
\text { Var }\end{array}$ & $\begin{array}{l}15 \\
14\end{array}$ & $\begin{array}{l}8.00 \pm 3.64 \\
7.50 \pm 2.82\end{array}$ & $\begin{array}{r}7(3-15) \\
7.5(3-13)\end{array}$ & 0.684 & $\begin{array}{l}3.40 \pm 1.06 \\
3.43 \pm 1.02\end{array}$ & $\begin{array}{l}3(2-5) \\
3(2-5)\end{array}$ & 0.880 \\
\hline Forniks & $\begin{array}{l}\text { Yok } \\
\text { Var }\end{array}$ & $\begin{array}{c}22 \\
7\end{array}$ & $\begin{array}{l}7.73 \pm 3.34 \\
7.86 \pm 3.08\end{array}$ & $\begin{array}{r}6.5(3-15) \\
8(3-13)\end{array}$ & 0.928 & $\begin{array}{l}3.41 \pm 1.02 \\
3.43 \pm 1.13\end{array}$ & $\begin{array}{l}3(2-5) \\
3(2-5)\end{array}$ & 0.980 \\
\hline Korpus kallosum & $\begin{array}{l}\text { Yok } \\
\text { Var }\end{array}$ & $\begin{array}{c}4 \\
25\end{array}$ & $\begin{array}{r}10.50 \pm 3.87 \\
7.32 \pm 2.97\end{array}$ & $\begin{array}{r}10.5(6-15) \\
7(3-13)\end{array}$ & 0.066 & $\begin{array}{l}3.50 \pm 1.29 \\
3.40 \pm 1.00\end{array}$ & $\begin{array}{r}3.5(2-5) \\
3(2-5)\end{array}$ & 0.879 \\
\hline
\end{tabular}

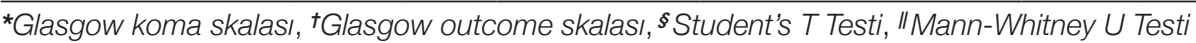

işlevlerin kötü olduğunu göstermektedir. Bu hastaların yoğun bakım yatışı sonrası rehabilitasyon ve taburculuğa hazırlanması da uzun sürmekte ve uzamış hastane yatıșlarına sebep olmaktadir.

Diffüz aksonal hasar saptanan grupta incelenen vital bulgular ve laboratuvar bulguları taburculuktaki kognitif durum ile ilişkilendirilememiştir. Ancak GKS ve PRISM skorları ile hastane yatış süresinin GOS ile anlamlı korelasyonu saptanmış olup, yine bu sonuç DAH ile başvuran hastalarda başvuru klinik değerlendirmesinin prognoz ile ilgili öngörüde bulunmaya yardımcı olabileceğini düşündürmektedir.

Çocuk kafa travması hastalarında MRG lezyon sayısı ve volümünün GKS ve kognitif işlev ile ilişkisini gösteren veriler olmakla beraber, çalışmamızda DAH (+) hastalarda toplam lezyon yükü ile GKS ya da GOS arasında anlamlı bir ilişki gösterilememiştir (11). Bu konunun DAH'ı bulunan daha geniş hasta serilerinde ve farklı görüntüleme yöntemleriyle yapılacak karşılaştırmalar ile çalışııması gerekmektedir.

Talamus ve beyin sapında lezyon bulunan hastalarda GKS anlamlı düşük bulunurken ( $p=0.019, p=0.036)$, herhangi bir bölgede lezyon varlığı ile GOS arasında ilişki gösterilememiştir. Yetişkinlerde de lezyonların yerinin prognozla ilişkisini gösteren çalışmalar olmakla beraber, özellikle çocukluk ve ergenlik çağındaki hastalarda yapılan çalışmalar ön planda bazal ganglionlar, beyin sapı ve talamus gibi yapılardaki hasarın uzun dönem prognozla ilişkili olduğunu göstermektedir $(8,12-14)$. Çalışmamızda kısa dönem prognoz göstergesi olarak GOS ile lezyon bölgesi arasında ilişki gösterilememesi belirli bir bölgedeki lezyona yönelik tedavi yaklaşımının değiştirilmesinin kısa dönem sonucu değiştirmeyeceğini düşündürmektedir. Ancak merkezimizde standart olarak yapılan difüzyon $M R G$ ve SWl görüntüleme yöntemi dışında seçilmiş hastalarda uygulanabilecek difüzyon tensor görüntüleme ve MR spektroskopi gibi ileri MR görüntüleme yöntemleri ile konvansiyonel MRG görüntülerine yansımayan DAH bulguları, etkilenen alanın genişliği saptanarak DAH lezyonlar ile uzun dönem kognitif hasar arasında ilişkilendirme yapılmasının gelecekte planlanacak çalışmaların konusu olabileceğini düşünmekteyiz (14-18).

Çalışmamızın kısıtlayıcı yönü prognozla ilgili skorun yalnızca hastane taburculuğunda kaydedilmiş olması ve uzun dönem prognozla ilgili karşılaştırma yapma imkanı bulunmamasıdır. Ayrıca görüntüleme yöntemleri açısından bu hastaların zaman içinde izleminde saptanacak değişikliklerin prognoz ile ilişkisi incelenmelidir. Anlamlı sonuçlara kısa sürede ulaşmak 
açısından, özellikle diffüz aksonal hasar hasta grubunda hasta sayısını artırmak için bu çalışmalar ulusal düzeyde çok merkezli olarak planlanabilir.

Çalışmamızın sonuçları DAH'ın hafif kafa travmalarına göre daha ciddi nörokognitif bozukluğa sebep olduğunu ve uzun hastane yatışı ve rehabilitasyon gerektirdiğini göstermektedir. Ancak prognoz ve kalıc hasar için belirleyici faktörler konusunda bilgilerimiz sınırlıdır. Bu hastalarda tedavi hedeflerini belirlemek için, DAH'da değişik görüntüleme yöntemleri ile saptanan bulguların kognitif hasarla ilişkisini gösterecek geniş kohort çalışmalara intiyaç vardır.

\section{KAYNAKLAR}

1. Kochanek PM, Tasker RC, Carney N, Totten AM, Adelson PD, Selden NR, et al. Guidelines for the Management of Pediatric Severe Traumatic Brain Injury, Third Edition: Update of the Brain Trauma Foundation Guidelines, Executive Summary. Neurosurgery 2019;84:1169-78.

2. Vavilala MS, Kernic MA, Wang J, Kannan N, Mink RB, Wainwright MS, et al. Pediatric Guideline Adherence and Outcomes Study. Acute care clinical indicators associated with discharge outcomes in children with severe traumatic brain injury. Crit Care Med 2014;42:2258-66.

3. Kannan N, Wang J, Mink RB, Wainwright MS, Groner JI, Bell MJ, et al; PEGASUS (Pediatric Guideline Adherence Outcomes) Study. Timely Hemodynamic Resuscitation and Outcomes in Severe Pediatric Traumatic Brain Injury: Preliminary Findings. Pediatr Emerg Care 2018;34:325-9.

4. Moran LM, Babikian T, Del Piero L, Ellis MU, Kernan CL, Newman $\mathrm{N}$, et al. The UCLA study of Predictors of Cognitive Functioning Following Moderate/Severe Pediatric Traumatic Brain Injury. J Int Neuropsychol Soc 2016;22:512-9.

5. Wainwright MS, Grimason M, Goldstein J, Smith CM, Amlie-Lefond C, Revivo G, et al. Building a pediatric neurocritical care program: a multidisciplinary approach to clinical practice and education from the intensive care unit to the outpatient clinic. Semin Pediatr Neurol 2014;21:248-54.

6. Pineda JA, Leonard JR, Mazotas IG, Noetzel M, Limbrick DD, Keller MS, et al. Effect of implementation of a paediatric neurocritical care programme on outcomes after severe traumatic brain injury: a retrospective cohort study. Lancet Neurol 2013;12:45-52.
7. Davceva N, Basheska N, Balazic J. Diffuse axonal injury-A distinct clinicopathological entity in closed head injuries. Am J Forensic Med Pathol 2015;36:127e33.

8. Vander Linden C, Verhelst H, Genbrugge E, Deschepper E, Caeyenberghs $\mathrm{K}$, Vingerhoets $\mathrm{G}$, et al. Is diffuse axonal injury on susceptibility weighted imaging a biomarker for executive functioning in adolescents with traumatic brain injury?. Eur J Paediatr Neurol 2019;23:525-36.

9. Dennis EL, Babikian T, Giza CC, Thompson PM, Asarnow RF. Diffusion $\mathrm{MRI}$ in pediatric brain injury. Childs Nerv Syst 2017;33:1683-92.

10. Weeks D, Sullivan S, Kilbaugh T, Smith C, Margulies SS. Influences of developmental age on the resolution of diffuse traumatic intracranial hemorrhage and axonal injury. I Neurotrauma 2014;31:206-14.

11. Beauchamp MH, Beare R, Ditchfield M, Coleman L, Babl FE, Kean $M$, et al. Susceptibility weighted imaging and its relationship to outcome after pediatric traumatic brain injury. Cortex 2013;49:5918.

12. Moen KG, Brezova V, Skandsen T, Haberg AK, Folvik M, Vik A. Traumatic axonal injury: the prognostic value of lesion load in corpus callosum, brain stem, and thalamus in different magnetic resonance imaging sequences. J Neurotrauma 2014;31:1486e96.

13. Abu Hamdeh S, Marklund N, Lannsjo M, Howells T, Raininko R, Wikstrom J, et al. Extended anatomical grading in diffuse axonal injury using MRI: hemorrhagic lesions in the substantia nigra and mesencephalic tegmentum indicate poor long-term outcome. J Neurotrauma 2017;34:341e52.

14. Babikian T, Freier MC, Tong KA, Nickerson JP, Wall CJ, Holshouser $\mathrm{BA}$, et al. Susceptibility weighted imaging: neuropsychologic outcome and pediatric head injury. Pediatr Neurol 2005;33:18494.

15. Dennis EL, Hua X, Villalon-Reina J, Moran LM, Kernan C, Babikian $\mathrm{T}$, et al. Tensor-Based Morphometry Reveals Volumetric Deficits in Moderate-Severe Pediatric Traumatic Brain Injury. J Neurotrauma 2016;33:840-52.

16. Dennis EL, Jin Y, Villalon-Reina JE, Zhan L, Kernan CL, Babikian $\mathrm{T}$, et al. White matter disruption in moderate/severe pediatric traumatic brain injury: advanced tract-based analyses. Neuroimage Clin 2015;7:493-505.

17. Dennis EL, Ellis MU, Marion SD, Jin Y, Moran L, Olsen A, et al. Callosal Function in Pediatric Traumatic Brain Injury Linked to Disrupted White Matter Integrity. J Neurosci ;35:10202-11.

18. Babikian T, Alger JR, Ellis-Blied MU, Giza CC, Dennis E, Olsen A, et al. Whole Brain Magnetic Resonance Spectroscopic Determinants of Functional Outcomes in Pediatric Moderate/Severe Traumatic Brain Injury. J Neurotrauma 2018;35:1637-45. 